\section{Banning mobile phones in schools: evidence from regional-level policies in Spain}

\author{
Pilar Beneito \\ Universitat de València \& ERICES, Valencia, Spain, and \\ Óscar Vicente-Chirivella \\ Universitat de València, Valencia, Spain
}

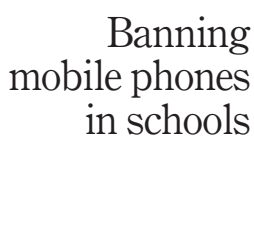

153

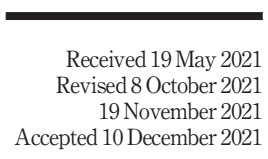

\begin{abstract}
Purpose - The autonomous governments of two regions in Spain established mobile bans in schools as of the year 2015. Exploiting the across-region variation introduced by such a quasi-natural experiment, this study aims to perform a comparative-case analysis to investigate the impact of this non-spending-based policy on regional Programme for International Student Assessment (PISA) scores in maths and sciences and bullying incidence.

Design/methodology/approach - The authors apply the synthetic control method and diff-in-diff estimation to compare the treated regions with the rest of regions in Spain before and after the intervention.

Findings - The results show noticeable reductions of bullying incidence among teenagers in the two treated regions. The authors also find positive and significant effects of this policy on the PISA scores of the Galicia region that are equivalent to $0.6-0.8$ years of learning in maths and around 0.72 to near one year of learning in sciences.

Originality/value - To the best of the author's knowledge, this is the first empirical study analysing the impact of mobile phone bans in schools on bullying cases, exploiting variation across regions (or other units), years and age intervals. Besides, the scarce formal evidence that exists on the consequences of the mobile phones use in students' academic achievement comes from a micro perspective, while the paper serves as one more piece of evidence from a macro perspective.
\end{abstract}

Keywords School bullying, Comparative-case studies, Maths and sciences skills, Regional-level policies

Paper type Research paper

\section{Introduction}

The question of whether or not to ban mobile phones' usage in schools is on the current agendas of education policy mandates and has generated recent debates in many countries [1]. Beyond particular policies at the individual school level, governments in some countries or some states/regions banned mobile phones in schools in recent years. For instance, the Israeli

(C) Pilar Beneito and Óscar Vicente-Chirivella. Published in Applied Economic Analysis. Published by Emerald Publishing Limited. This article is published under the Creative Commons Attribution (CC BY 4.0) licence. Anyone may reproduce, distribute, translate and create derivative works of this article (for both commercial and non-commercial purposes), subject to full attribution to the original publication and authors. The full terms of this licence maybe seen at http://creativecommons.org/ licences/by/4.0/legalcode

JEL classification - C21, H75, I21, I28, J24

Pilar Beneito acknowledges financial support from Grant ECO2017-86793-R funded by MCIN/AEI/ $10.13039 / 501100011033$ and by "ERDF A way of making Europe", and from Generalitat Valenciana (PROMETEO - 2019-95).

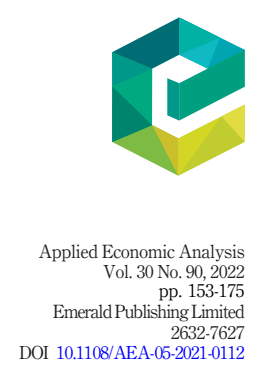


AEA

30,90

Ministry of Education decided to ban mobile phones during the school day in 2016. In France, the policy came into effect during the beginning of the 2018-2019 school year and impacted students over 15. In 2019, four states in Australia banned smartphones for students up to 18 years. Instead, in 2015 the Mayor of New York removed a 10-year ban of phones in schools, claiming that abolition could decrease inequality (Allen, 2015). Governments pursue two main goals with this type of policy intervention: improving academic performance and reducing bullying, which are precisely the impacts that we address in this paper.

An effective control of the use of new mobile technologies made by students at schools can constitute a new policy tool to complement resource-based interventions by governments. This might become specially interesting if, as some authors have pointed out, the room for resource inputs to affect human capital formation can be of limited scope in some settings. In this line, Woessmann (2016) provides evidence that students in a wide set of countries overperform students in the USA while spending considerably less on schools per student (OECD, Organisation for Economic Co-operation and Development, 2013). This author concludes that a wide range of additional factors, including institutional features of school systems, may entail major implications for the effectiveness of education investments.

In this paper, we provide regional-level evidence of the impact of a non-spending-based policy intervention directly aimed at enhancing academic outcomes and, simultaneously, students' social behavior. In particular, we investigate the impact of banning mobile phones in schools on students' academic achievement and school bullying incidence. To this end, we use as comparative case studies two regions in Spain (Galicia and Castilla La Mancha, CLM henceforth) whose regional governments passed laws to ban mobile phones in primary and secondary educational centers towards the end of the year 2014 (CLM) and beginning of the year 2015 (Galicia). In the rest of Spanish regions other than Galicia and CLM, the use of mobile phones by students in schools is not regulated [2].

The mentioned interventions in Galicia and CLM constitute a quasi-natural experiment that allows us to take the case of Spain and their regions as an excellent lab for the analysis of this highly debated policy. One advantage of using regional-level data within a country is that it permits us to examine differences among units that are comparable in some fundamental institutional and cultural traits. That is, it avoids the huge unobserved country heterogeneity affecting cross-country analysis (Di Liberto, 2008; and Gennaioli et al., 2013). Galicia and, particularly so, CLM are regions with wealth levels below the Spanish average (over the analyzed period, Galicia is the 9th and CLM is the 14th out of the 17 Spanish regions in the ranking of real income per capita). Hence, the analysis of a policy intervention that could impact educational development, while not based on large investments of economic resources, entails great interest in the case of disadvantaged regions.

To conduct the analysis, we construct a region-level panel data for our outcome variables of interest as well as for several regional-year control variables using official data sources for the 17-Spanish regions before and after the mobile phone bans (with the exceptions that we will comment below). We compare the regions where the policy was implemented (the treated regions, henceforth) with the rest of regions in Spain before and after the intervention took place.

For the analysis of academic outcomes, we use the scores in maths and sciences obtained by 15-year-old Spanish students in the five The Programme for International Student Assessment (PISA) installments conducted from 2006 to 2018 (every three years). The PISA scores [international testing entered by the Organisation for Economic Co-operation and Development (OECD) in 2000] have the advantage of their international comparability and are aimed at evaluating competencies and skills rather than locally designed academic goals. In addition, the focus on middle-school students is of special interest in the case of 
Spain, given the importance of secondary education in the Spanish labor market (LópezBazo and Moreno, 2012).

As participation in the PISA installments is not mandatory, the CLM region did not participate neither in 2006 nor in 2012, which poses us problems for the analysis of the preintervention trends in the academic achievement of students in this region. Fortunately, the data for the Galicia region is complete. Taking advantage of this, we apply both the synthetic control method (SCM, henceforth, Abadie and Gardeazábal, 2003; Abadie et al., 2010) and differencesin-differences (DID) regression analysis (DID, henceforth) to evaluate the impact of the mobile phones ban on students' PISA scores in this region. In the case of the CLM region, we will present below some estimates of the effect of interest using DID regressions, though we take with special caution these results due to the mentioned data limitations.

For the analysis of bullying, we apply DID regression to both Galicia and CLM. The outcome variables are, in this case, officially reported cases for every 10,000 school students in three age intervals (covering from 6 to 17 years old), spanning over the period 2012-2017. This information, by region and year, was requested to the Spanish police forces and made public by the Spanish Ministry of Education in 2018, following a specific demand of information in this regard made by a member of the parliament. Thus, the region-year-age level data on bullying used in this paper is quite unique. To our knowledge, this is the first empirical study exploiting variation across regions (or other units), years and age intervals on bullying cases.

There exists scarce formal evidence on the consequences of the mobile phone use in students' academic achievement. This is especially important on primary and secondary education since it is at this age when children initiate the use of these devices, and also where the existing evidence is particularly scarce [3]. The use of mobile devices is not necessarily detrimental for education when correctly designed. For example, the use of certain Apps could make children more involved in their learning process and increase the enjoyment from studying. In addition, the immediate access to an infinite source of information can complement instruction received at schools and improve the learning process of students (Milrad, 2003). Furthermore, students can rapidly share information not only with other students but also with teachers, which could lead to a more efficient studying and collaboration (Chen and Ji, 2015; Lepp et al., 2015).

Positive effects on academic achievement can also come from potential complementarities between the use of mobile phones and the development of other technological competencies on the part of students, provided that the latter enhances academic outcomes. In this regard, our paper is also related to the literature on the impact of technology on students' outcomes. Results from this literature, however, are far from conclusive [4]. Some results seem to indicate that what actually matters is not the technology on its own but rather the structured or unstructured use of a particular technology. For instance, Barrow et al. (2009) find that students randomly assigned to computer-aided instruction using an algebra program largely improve on algebra test scores compared to the students receiving traditional instruction. Also, Muralidharan et al. (2019) show that well-designed, technology-aided instruction programs sharply improve test scores in middle-school grades [5]. Finally, Fryer (2013) set an experiment where a treated group of students were provided with free mobile phones where they received daily information about human capital and future outcomes, while the control group did not receive this information. Results show that although students in the treated group did not improve attendance, behavioral incidents or test scores, they reported being more focused and working harder in school. Cho et al. (2018) offer a meta-analysis looking at the effect of mobile devices on student achievement in language learning in primary, secondary and post-secondary education. They find a positive effect of using mobile devices on language 
AEA

30,90

acquisition and language-learning achievement and, thus, conclude that the use of mobile devices could facilitate language learning.

However, even if mobile phones are used to structured activities, allowing them in schools opens the door to be used for recreational purposes as well, thus generating distraction. In fact, according to research in computer science and educational studies, the detrimental effects of mobile phones in schools are explained because multi-tasking or taskswitching decrease learning (Jacobsen and Forste, 2011; Junco and Cotten, 2011, 2012; Rosen et al., 2013; Wood et al., 2012). For example, notifications on the smartphone are a constant distraction limiting students' attention during class and/or study time (Junco and Cotten, 2012). Besides, the desire to continuously interact with the rest of the world may lead to a level of concentration that is lower than needed to achieve a good study performance (Chen and Yan, 2016) [6]. Finally, unmotivated students have a great temptation at their fingertips to switch off from the lesson and play games, surfing the internet or use social networks (Hawi and Samaha, 2016). Some experimental papers present additional evidence pointing in this direction (Wood et al., 2012; Kuznekoff and Titsworth, 2013; Levine et al., 2013; Amez and Baert, 2020, for a survey of papers published in this field).

Recent direct evidence on the causal effects of banning mobile phones policies on academic outcomes are provided by Beland and Murphy (2016), Kessel et al. (2020) and Abrahamsson (2020). Beland and Murphy (2016) investigate the impact of banning mobile phone use in schools on student academic results using a sample of 91 schools in four English cities. In particular, they analyze the gains in test scores across and within schools before and after mobile phones bans were introduced, and find positive effects of banning the use of mobile phones on such academic results. Kessel et al. (2020) replicate the same study with data for Sweden but, contrary to Beland and Murphy (2016), do not find any significant effect of the ban on students' academic performance. Abrahamsson (2020) studies the effect of banning smartphones in the classroom on students' educational outcomes in Norwegian middle schools, and shows that the banning policies significantly increased girls' grade point average and increased their likelihood of attending an academic high school track. Interestingly, the magnitude of her estimates is larger among low-ability students and students from low socioeconomic backgrounds.

Research on the relationship between the use of mobile phones in schools and bullying is even scarcer. A possible explanation for this lack of studies is the difficulty in obtaining reliable data on bullying cases. The link between mobile phones in schools and bullying is very intuitive: given that cyberbullying already represents $20 \%$ of bullying cases (Cook, 2020) and that smartphones are one of the main conduits for cyberbullying among children (Adams, 2019), the removal of the instrument should be expected to influence the number of bullying cases. In spite of the scarcity of research on this topic, the analysis of the possible actions that may control bullying is of primary importance, given the severe and long-term consequences for those suffering it as a child or teenager in the form of psychological and emotional health, education and future earnings (Drydakis, 2014). To the best of the authors knowledge, the paper by Abrahamsson (2020) is the unique reference in the literature that carries out a causal analysis of the link between banning mobile phones at schools and bullying. This author finds that banning mobiles phones have the potential to reduce school bullying among middle-school students. Further, and interestingly enough, she finds that the policy is effective only when it is implemented as a clear prohibition to bring the device (mobile phone) into school.

As mentioned before, other studies have already looked at the effect of banning mobile phones in schools on student achievements using micro data. Unfortunately, we do not have data at such a disaggregated level. However, with the data we have and the techniques we use in our analysis, we can still provide suggestive evidence on whether a regional-level policy can 
have effects on our variables of interest. Therefore, one of the contributions of our paper is offering a new perspective by looking at differences between regions rather than differences across schools and students. By using the PISA assessments, which are homogenous across regions, we avoid all the possible concerns about different exams in different schools and the self-selection of students in certain schools. One more novelty of our study is that we are able to check the bullying effects in different age groups: under-12, 12-14 and from 15-17 years old. Given that among children under 12 years old the use of mobile phones is not extended yet in Spain, we do not expect significant results for the under-12 group. Thus, results for this age group may serve as a placebo check in our analysis below [7].

Thus, our paper contributes by highlighting the potential effects of a non-spending-based policy on the educational attainment of middle-school students. In addition, our analysis also addresses the potential effects of these policies in enhancing the school social environment, an indirect though potentially relevant factor affecting educational outcomes. The policy analyzed in this paper is a timely issue of primary relevance looking ahead on a future where technology will dominate the workplace, and everything will be connected and data-driven.

To anticipate our results, we find that, after less than three years since the mobile phones ban was in force (from 2015 to 2017), students' PISA scores in Galicia improved by around 10 points in maths and 12 points in sciences as compared to a synthetic Galicia that had followed exactly the same trend in these scores before the intervention. Following Woessmann (2016), these estimated effects are equivalent to $0.6-0.8$ years of learning in maths and around 0.72 to near one year of learning in sciences. Jointly with this, bullying incidence fell by around $9.5 \%$ to $18 \%$ over its pre-intervention levels among teenagers in the treated regions.

It is worth mentioning that the prohibition policy analyzed here was not a categorical prohibition since it allowed devices to be used inside the schools as a learning tool for educational purposes. Could it be the case that Galicia and CLM decided to use the devices in this direction to a larger extent since the year 2015? According to the INE [8], this does not seem to have been the case: the percentage of secondary schools that allowed students to use mobile devices with educational purposes during 2016/2017 (first year with available information) were around $33 \%$ and $36 \%$ for Galicia and CLM, respectively, while the national average was $34 \%$. Unfortunately, we do not have information on whether these schools ended up using mobile phones with educational purposes or not or to what extent.

Even if the policy was not a categorical prohibition, it certainly provides the legal coverage for centers and instructors to effectively limit students' misbehaviors in educational centers. From this perspective, it seems sensible to assume that the percentage of educational centers/ teachers controlling the use of mobile phones have been clearly higher in the regions with and after the policy. In any case, our estimates have to be framed within the limitation of the available information, and taken not as a response to the prohibition of mobile phones per se but, instead, to the enforcement of using mobile phones for learning purposes only.

The rest of the paper is organized as follows. Section 2 provides a description of the materials and methods used in this paper. Section 3 presents the results, and finally, Section 4 concludes and discusses our main results.

\section{Data and methods}

\subsection{Region-year panel data}

Spain is administratively organized in 17 regions (NUTS-2 regions, in the Eurostat's classification, referred to as "Comunidades Autónomas" in Spain). The regional governments are autonomous, among other aspects, to decide upon the regulation and administration of education in all its extension, levels and grades [9]. On this base, two Spanish Regional Governments (CLM and Galicia) passed laws to ban in all the educational 
AEA

30,90

centers of primary and secondary stages the use of mobile phones by students as of 2015 [10]. In the rest of the regions, the use of mobile phones is unregulated, in most of the cases allowing each school to decide upon the use of mobile phones [11]. To conduct the analysis, we create a region-level panel using official sources of data for all the 17-Spanish regions before and after the mobile phones-ban, with the exceptions that we comment below. We set the year 2015 as the first year where the intervention could have had an effect on our outcome variables [12].

For the analysis of academic outcomes, we use the scores obtained by Spanish school students in the PISA installments from 2006 to 2018 [13]. We use in total five PISA assessments, corresponding to years 2006, 2009, 2012, 2015 and 2018. We attribute the scoring of every PISA assessment to the academic achievement of students developed up to the previous year. For instance, the results of PISA-2018 are considered to measure the academic competencies acquired by students up to the year 2017 (included). In accordance with this, we lag the PISA scores of a given call one year. After this, we construct a yearly time series of PISA scores interpolating the scores from one PISA wave to the next, under the assumption that the improvement or the decline in academic competencies evaluated by PISA occurs gradually between each pair of consecutive assessments [14]. We finally use in the analysis the series of constructed scores spanning 2006-2017. Unfortunately, the CLM region did not participate in two out of the five PISA installments (2006 and 2012), so that the series of academic results constructed for this region present limitations when it comes to track their temporal evolution. Thus, we will take with special caution the analysis of academic results in the case of the CLM region [15].

For the analysis of bullying, we use the information provided by the Spanish Ministry of Education in 2018 about officially reported cases of school bullying from 2012 to 2017. This data was requested in 2018 by the Spanish Ministry of Education to the Spanish national and local police forces to respond a specific query about this social problem made in the parliament [16]. The regions of Cataluña and País Vasco did not report this information, and, for this reason, these two regions are not included in our analysis of bullying. The cases were reported separately for four age intervals, namely, school students $6-8,9-11,12-14$ and 15-17 years-old. We define three age groups for our analysis below: on the one hand, primary schools students (under-12 years old), and, on the other hand, secondary school students, distinguishing in this case the two age groups mentioned. For each of these age intervals, we construct the number of cases for every 10,000 school students of that age [17].

Finally, we construct three additional covariates, with across region and yearly variation, to be used in the SCM and DID estimation. The first variable is the percentage of children over 10 owning a mobile phone [18]. This variable aims at capturing the extent to which the use of mobile phones, in or out of schools, is generalized among the children of a region and year. Second, we construct series of public real spending (excluding the financial component [19]) on education in the primary and secondary stages of education per school-student [20]. This variable tries to capture changes in academic results or bullying that might respond to differences in the regional level of investments in education. Finally, we also construct series of households' per capita real disposable income for each region-year [21]. Nominal variables are deflated using CPI indexes at the region-year level.

Figure 1 and Table 1 show the relative standing of the two treated regions, Galicia and CLM, in the Spanish economy in terms of households' real income per capita, public spending per student on education by region and percentages of children and adolescents who use mobile phones. The period represented in the maps spans 2012-2017. In Figure 1, the regions have been classified into four quartiles of the distribution of the variable in the heading of each map. Sorting income in decreasing order, the region of CLM lies within the 


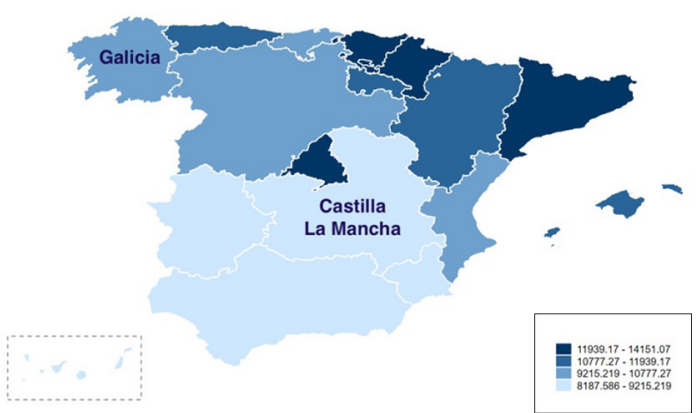
in schools

Public spending per capita on education by region

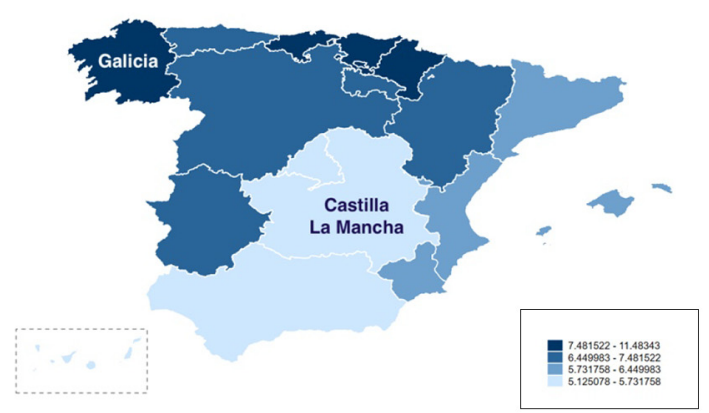

Mobile use by region

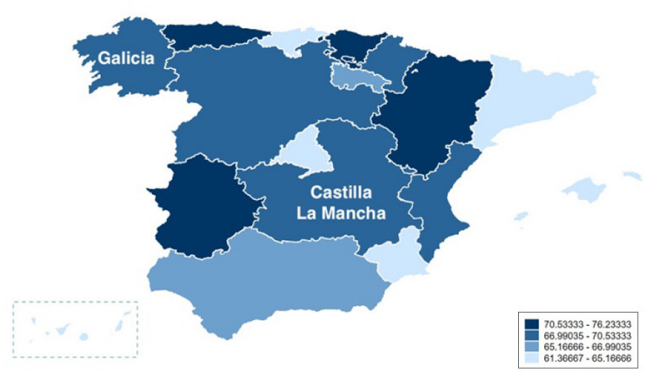

Notes: The maps show the relative standing of the Spanish regions in terms of income (real households' income per capita), public spending on education (real and per student) and percentage of mobile users among children and adolescents. The period depicted is 20122017

Source: own elaboration from INE, in all the cases

Figure 1.

Households' income, public spending on education and percentage of mobile users among children and adolescents 


\begin{tabular}{|c|c|c|c|c|c|c|}
\hline \multirow{4}{*}{$\begin{array}{l}\text { AEA } \\
30,90\end{array}$} & & & & & & \\
\hline & & \multicolumn{5}{|c|}{ Years 2012-2017 } \\
\hline & & & & & & Difference \\
\hline & & Mean & $\mathrm{SD}$ & Mean & $\mathrm{SD}$ & in means \\
\hline \multirow{4}{*}{160} & Income per person & & & & & \\
\hline & Galicia region & 9.225 & 0.015 & 9.247 & 0.017 & 0.022 \\
\hline & CLM region & 9.047 & 0.033 & 9.068 & 0.024 & 0.021 \\
\hline & $\begin{array}{l}\text { Rest (15 regions) } \\
\text { Public snending in }\end{array}$ & 9.261 & 0.187 & 9.286 & 0.179 & 0.024 \\
\hline \multirow[b]{7}{*}{$\begin{array}{l}\text { Table } 1 \text {. } \\
\text { Descriptives on the } \\
\text { control variables }\end{array}$} & Galicia region & 7.400 & 0.185 & 7.619 & 0.164 & 0.219 \\
\hline & CLM region & 5.656 & 0.276 & 5.791 & 0.081 & 0.134 \\
\hline & Rest (15 regions) & 6.872 & 1.570 & 7.086 & 1.477 & 0.241 \\
\hline & Galicia region & 65.91 & 4.38 & 68.50 & 1.90 & 2.58 \\
\hline & CLM region & 66.85 & 7.86 & 70.50 & 2.95 & 3.64 \\
\hline & Rest (15 regions) & 65.78 & 6.02 & 69.37 & 5.56 & 3.62 \\
\hline & \multicolumn{6}{|c|}{$\begin{array}{l}\text { Notes: Income per person: (log of) households' per capita real disposable income (Source: INE, Contabilidad } \\
\text { regional de los hogares.); Mobile users (\%): percentage of children over } 10 \text { years old owning a mobile } \\
\text { (Source: INE, Encuesta sobre equipamiento y uso de tecnologías de información y comunicación en los } \\
\text { hogares). Public spending on education: public real spending (excluding the annual financial envelope) on } \\
\text { education in the primary and secondary stages of education per school-student (Source: own elaboration } \\
\text { from INE, Estadistica de gasto público en educación, EDUCAbase). All variables are at the region-year level; } \\
\text { nominal variables are deflated using CPI indexes at the region-year level'. Mobile users' figures refer to the } \\
\text { period } 2006 \text { (when thev started to appear) to } 2017\end{array}$} \\
\hline
\end{tabular}

fourth quartile, that is, among the poorest Spanish regions, while Galicia lies within the third quartile in this ranking. Further, as can be seen in Table 1, income levels have remained quite stable both in the treated and in the untreated regions, and also over the six years period around the implementation of the policy (2012-2017).

In terms of educational public spending, CLM also lies within the last quartile, while Galicia seems to have made a considerable effort during this period in terms of educational spending on primary and secondary education, given that the region is in the first quartile in terms of this type of spending per student. It is unlikely that the income levels of Galicia unless they appreciably start increasing, could sustain in time such levels of educational public spending. Table 1 shows that these levels of Galician public spending on primary and secondary education have increased over the period as much as in the rest of regions in Spain. In any case, to reassure that these differences do not confound our results of interest, we partial out the effect of public educational spending in our estimations below.

Finally, and as regard the use of mobile phones in the regions, the main conclusion we draw is that contrary to what could be expected, income not always correlates positively with mobile phones' usage. For instance, the region of Extremadura (on the South-West limiting with Portugal) is among the poorest regions in Spain while also among the regions with the most intense usage of mobile phones. The treated regions, Galicia and CLM, lie within the second quartile in this classification. Table 1 further shows that these percentages have been increasing in time and, apparently, at comparable rates in all the Spanish regions.

Next, Figures 2 and 3 display the sample distribution across regions of our two outcomes of interest, namely, PISA scores and bullying incidence, before and after the mobile phones ban. The PISA scale is standardized to have a mean of 500 and a standard deviation, SD, of 100 among all students in OECD countries (this standardization was done in 2003 in maths 

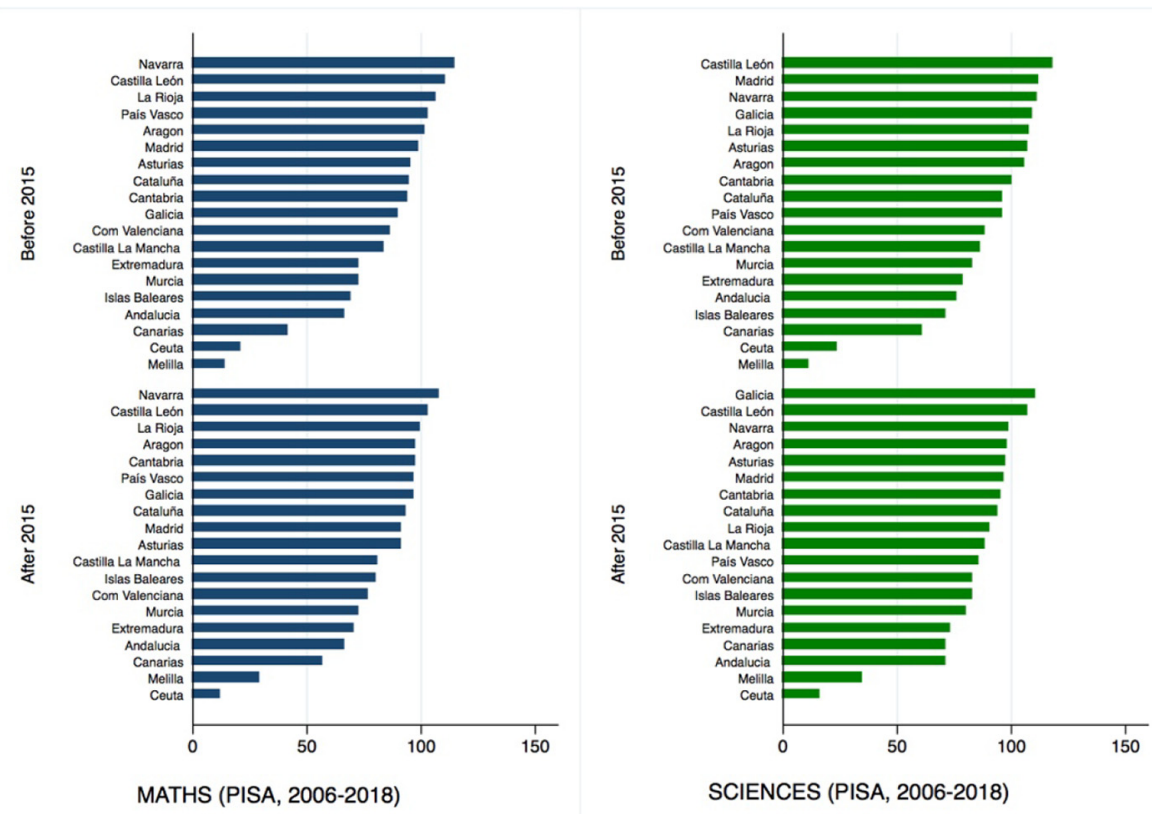

Note: The figures display the PISA scores in maths and sciences averaged over the years before (upper panels) and after (bottom panels) the intervention year 2015

\section{Banning mobile phones in schools}

Figure 2.

PISA Scores in maths and sciences from 2006 to 2018

and in 2006 in sciences). Figure 2 shows that, as compared to previous PISA installments (from 2006 to 2015), the scores obtained by Spanish students in PISA-2018 remained quite stable on average in maths, while in science the average Spanish score diminished by around five points (in our sample, average scores changed from 488.6 to 487.2 in maths and from 494.7 to 489.8 in sciences, before and after the year 2015, respectively). Galicia and CLM are among the regions that improved their position in the Spanish regional ranking with respect to their scores in previous PISA installments.

Figure 3 displays, on the left, the statistics for primary school students under-12 years old and, on the right, those corresponding to children and teenagers who are mobile phones users (12-17 years old). A first observation is that, as expected, reported cases of bullying are much less frequent among the smaller children. In our data, average bullying incidence is 10 times smaller among under- 12 children than among 12-17 years old teenagers. Second, we observe in both cases that the officially reported cases of bullying remained quite stable over the period of analysis; if anything, they slightly increased in the under-12 group (averages of 0.38 before 2015 and 0.48 after 2015 for the under- 12 group; averages of 3.90 and 3.93 for the older groups; vertical lines in the graphs indicate the sample averages). The right-hand side panel also shows that both Galicia and CLM overpassed by more the average line before 2015 than after that year.

At this descriptive level, however, we cannot discern to what extent the observed changes can be attributed to the mobile phones ban. Differences in (out of school) mobile phone use among children across regions and over time, in income levels or in educational 


\section{AEA}

30,90

\section{2}

Figure 3.

Cases of bullying per 10,000 individuals in each age-interval
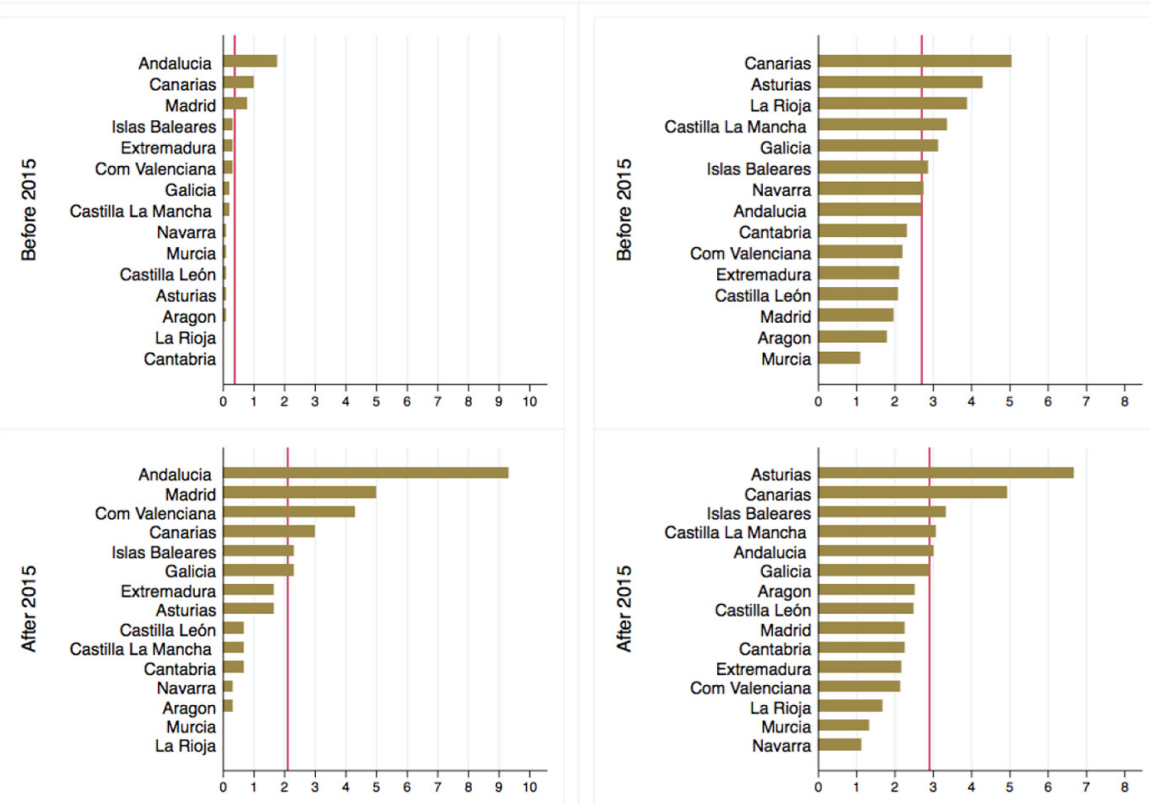

Age 6-8 (no mobile users)

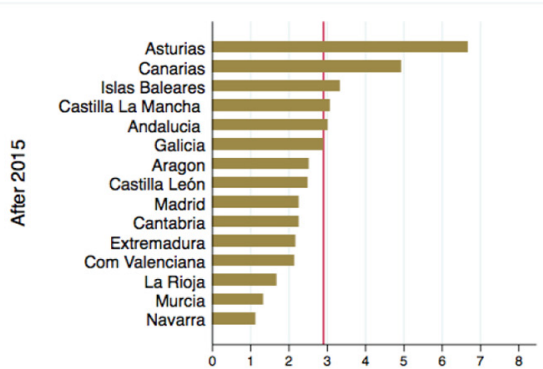

Age $9-17$ (mobile users)

Notes: The figures display the number of yearly reported cases reported per 10,000 school students averaged over the years before (upper panels) and after (bottom panels) the intervention year 2015

expenditures, for instance, are not controlled in the figures. In the next section, we describe the empirical strategy that we follow to identify the impact of the mobile phones ban.

\subsection{Synthetic control method}

For the analysis of academic outcomes, we focus specially in the case of Galicia, for which we count on a complete time series of observations (PISA scores in maths and sciences from 2006 to 2017). Our identification strategy relies primarily on the application of the SCM (Abadie and Gardeazábal, 2003; Abadie et al., 2010). The SCM is a statistical technique that has been specially designed to estimate the effects of events or policy interventions that take place at the aggregate level and affect to a small number of large units, such as cities, regions or countries. Thus, it constitutes one of the causal-identifying methods best suited to be applied to our sample data of regions [22].

The idea behind the SCM strategy is that the effect of an intervention can be measured through a comparison between the evolution of the outcome variable of interest in the unit affected by the policy intervention and a group of units similar to the treated unit that have not been treated. The main requirement to apply this methodology is that the evolution of the outcome variable for treated and untreated units can be properly tracked during the preintervention period. Two of the advantages of this methodology are, first, that it only requires data on an aggregate level (Abadie et al., 2010) and, second, that it solves the arbitrariness in the choice of the control units typically affecting comparative-case studies. 
Instead, the SCM conducts a formalized data-driven procedure that constructs a weighted combination of a small number of unaffected units, taken from the set of potential controls or donor pool, as the most appropriate unit of comparison [23].

In the SCM, the counterfactual outcome $Y_{i t}^{N}$ is estimated as the outcome corresponding to that synthetic unit. More formally, considering $(J+1)$ regions, with $(J=1)$ being the treated one, the synthetic control is constructed from a $(J \times 1)$ vector of weights, $\mathrm{W}=\left(w_{2},[\ldots], w_{J+1}\right)^{\prime}$ that allows us to define the estimators for $Y_{i t}^{N}$ and for the effect on the treated unit $\tau_{i t}$ as follows:

$$
\begin{gathered}
\widehat{Y_{j t}^{N}}=\sum_{j=2}^{J+1} \omega_{j t} Y_{j t} \\
\widehat{\tau_{1 t}}=\widehat{Y_{j t}^{N}}-\sum_{j=2}^{J+1} \omega_{j t} Y_{j t}
\end{gathered}
$$

where the weights are restricted to be non-negative and to sum to one.

To apply the SCM, we need a set of $k$ potential predictors of the pre-intervention outcome trends. As such predictors, we use past values of the own outcome of interest plus the covariates defined above (percentage of children using mobile phones, public spending on education and disposable real income per capita). The method uses a weighting-matrix, $\mathbf{V}$, that contains the relative importance of each of the $k$ predictors in constructing the synthetic control. The main challenge of the method is how to find the optimal weighting matrices $\mathbf{W}$ and $\mathbf{V}$. We follow Abadie et al. (2010), who propose choosing the $\mathbf{V}$ that minimizes the root mean squared prediction error (RMSPE) of the pre-intervention outcome between the treated unit and the control unit. Then, $\mathbf{W}$, which is a function of $\mathbf{V}$, is picked to minimize the RMSPE of the predictor variables for a given $\mathrm{V}$.

Below, after the SCM estimation and to evaluate the significance of our estimates, we report standardized $p$-values constructed from the distribution of placebo or permutation tests following Abadie et al. (2010). This is done by estimating the same model on each untreated unit with the same intervention years and period and removing the actual treated unit from the potential donor pool of these other units. These are non-parametric exact tests, which have the advantage of not imposing any distribution on the errors. If the effect of the intervention on the treated unit is significant (not observed by chance), we should observe that the probability of finding comparable estimated effects in other units is very low (Galiani and Quistorff, 2017, for further details).

Unfortunately, the available data for CLM does not allow us to trace out a fully reliable series of PISA assessments since students of this region did not participate in the PISA installments of the years 2006 and 2012. This prevents us from making a reliable pre-trend analysis for the CLM case. Thus, we do not apply the SCM to this case, although we will provide some evidence based on a DID regression for this region.

\subsection{Difference-in-differences analysis}

After the SCM, we apply DID analysis to the PISA scores of Galicia for the sake of comparison with the SCM and to the PISA scores of CLM. In the case of the bullying data, where the presample period is not long enough to apply the SCM, we also conduct DID estimation.

The DID equation can be written as follows: 


$$
Y_{i t}=\alpha+\beta \text { Post }_{t} \times D_{i}+\gamma x_{i t}+\delta_{i}+\tau_{t}+u_{i t}
$$

30,90

where subscripts $i$ and $t$ denote the region and year, respectively. The dependent variable, $Y_{i t}$, is our outcome of interest in each case, either students' PISA scores or officially reported cases of bullying. Post $t_{t}$ is a dummy-step variable taking on value 1 for the year of implementation and subsequent years (2015-2017); $D_{i}$ is a dummy variable for the treated region, capturing time-constant differences between it and the rest of regions if any. Vector $\boldsymbol{X}_{i t}$ contains three covariates, namely, the percentage of mobile phone usage by children in the region-year, real public spending on education in primary and secondary education and region-year per capita real disposable income. Finally, $\delta_{i}$ stand for region-fixed effects (thus absorbing time-constant differences between the treated region and the rest of regions), $\tau_{t}$ is a full set of year dummies and $u_{i t}$ stands for the $i i d$ error of the model. In equation (3), once region-level specific differences, common year effects and other region-year differences in covariates have been controlled for, parameter $\beta$ identifies the treatment effect.

In the estimation below, we also show the results for an extended specification of equation (3) where we add a term pre $_{t-1} \times D_{i}$ :

$$
Y_{i t}=\alpha+\beta_{0} \text { pre }_{t-1} \times D_{i}+\beta_{1} \text { Post }_{\mathrm{t}} \times \mathrm{D}_{\mathrm{i}}+\gamma \mathrm{x}_{\mathrm{it}}+\delta_{\mathrm{i}}+\tau_{\mathrm{t}}+\mathrm{u}_{\mathrm{it}}
$$

The added term is the product of a dummy variable taking on the value 1 for some preintervention years times the dummy of the treated regions. In particular, we define $p_{r-1} e_{t-1}$ as a dummy variable taking the value 1 for years 2012-2014 in our analysis of the PISA scores (and 0 otherwise), and a dummy variable taking the value 1 for the year 2014 in our analysis of bullying (and 0 otherwise). This term serves us to rule out the possibility that the differences between the treated and the control regions started to appear prior to the ban. In other words, the estimate of $\beta_{0}$ is expected to be non-significant for the DID estimation to be a valid identification strategy.

The equations above are estimated for Galicia and CLM separately, and in the analysis of bullying, we further estimate the model for the three mentioned age intervals: under-12, 12-14 and 15-17 years old school students.

\section{Results}

\subsection{Impacts on academic performance}

In Table 2 and Figure 4, we display the results for the SCM applied to Galicia. As already mentioned, the SCM provides a systematic data-driven procedure to create the (weighted) combination of regions that best resembles the actual Galicia before the implementation of the mobile phones ban. The SCM constructs the synthetic Galicia for PISA results on maths as a combination of Navarra (41.2\%), Canarias (21.6\%), La Rioja (14.4\%), Extremadura $(12.8 \%)$ and Cataluña $(10 \%)$; for the PISA results in sciences, it is a combination of CastillaLeón (79\%), Islas Baleares (17\%) Cataluña (3\%) and Madrid (1\%). All the other regions in the donor pool were assigned zero weights. The SCM estimation exhibits then sparcity in the choice of regions to construct the counterfactual (Abadie, 2021), and also, as can be seen at the bottom of Table 2 , a close match between the pre- and post-intervention values of the predictors and low pre-intervention prediction error (root of the mean square prediction error, RMSPE, of around 0.4 for outcome variables that have average values of around 490).

Figure 4 permits us to visualize the almost perfect fit between the treated unit (Galicia) and its synthetic counterpart in the pre-intervention period. However, after the ban, there is a positive gap in favor of the Galicia region in both PISA indicators. In maths, this positive gap seems to respond to a combination of increasing scores in the case of Galicia and 


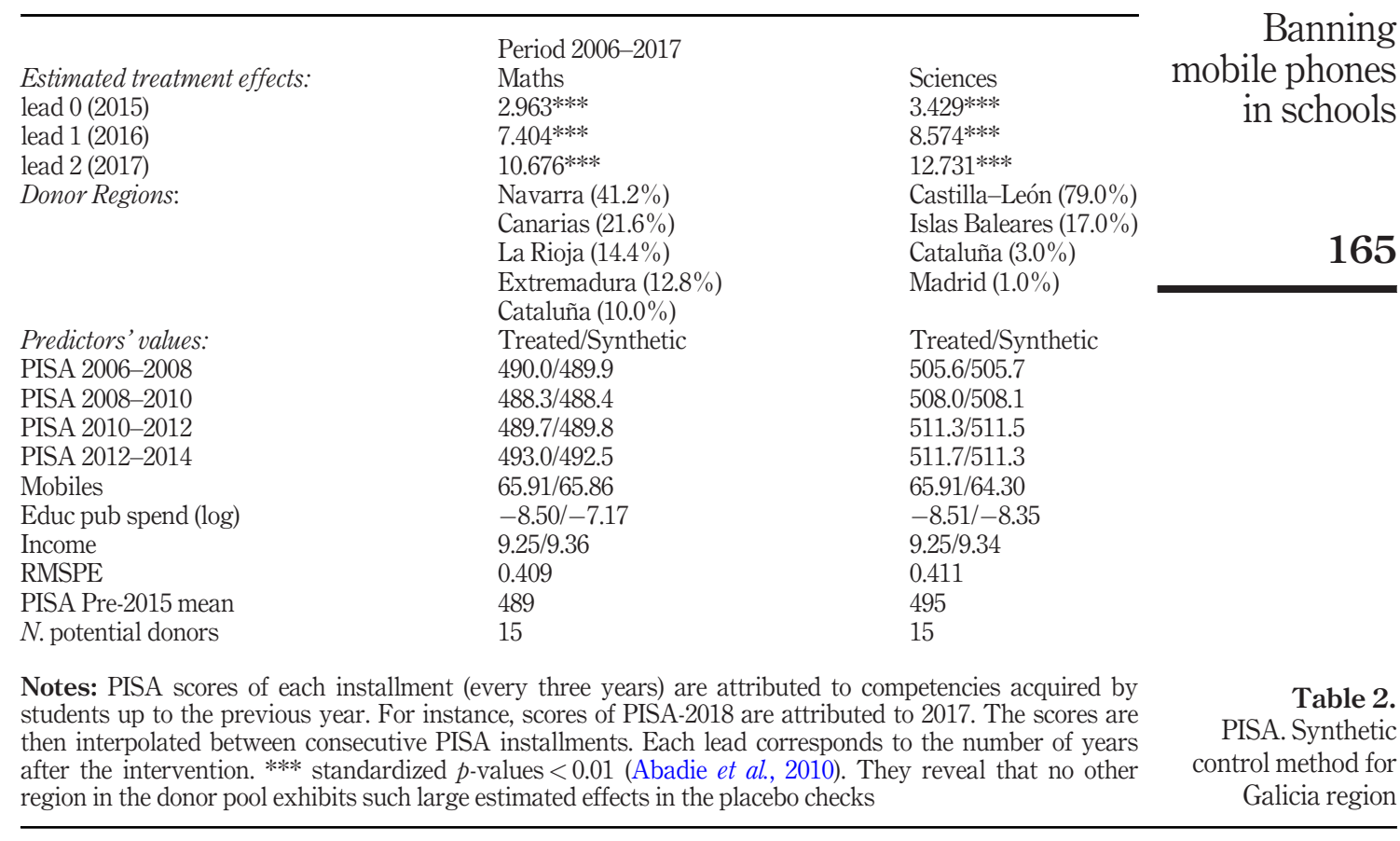

somewhat decreasing scores in the synthetic Galicia (though these latter scores do not fall below the pre-trend average values). In the case of sciences, the decline in the PISA results exhibited in the synthetic Galicia is more noticeable. This decline in Spanish students' PISA scores in the past years, and particularly in the 2018-call, has been explicitly highlighted (Stegmann, 2019). Further, this trend does not seem to be exclusive of the Spanish case. As documented by Rowley et al. (2019) and contrary to expectations -in authors' words-, few countries significantly increased their PISA scores in recent years, and in many of the cases, the change is indeed negative. If we had to think on a global common phenomenon affecting young teenagers, the outbreak of the use of mobile phones would be a candidate. Further, in the standard DID estimation applied to the PISA data that we offer below, we find that regions with a higher percentage of teenagers' mobile phones users have experienced, other things equal, a larger and significant decline on PISA results in the past years. Thus, one of the plausible explanations for the observed academic decline could be the intensification in the use of mobile phones among the youngest and the distraction that they introduce in their learning time. It follows that the control of their usage in school time might have allowed the treated region to escape from such declining trend.

The estimated effects are of an order of magnitude of around 10.7 and 12.7 points on maths and sciences, respectively, in the year 2017 (when the outcome takes the value of the PISA assessment of 2018). In addition, the $p$-values derived from the placebo tests in the SCM analysis indicate that for no other region, the SCM finds comparable results to the ones obtained for the treated region. Given that the average of PISA scores for Spanish students in maths and sciences are around 10-12 points below the international average of 500, the magnitude of the estimated effects would imply catching up with the OECD mean in a 
AEA

30,90

\section{6}

\section{Figure 4.}

Synthetic control method results for PISA assessments in maths and sciences in the region of Galicia
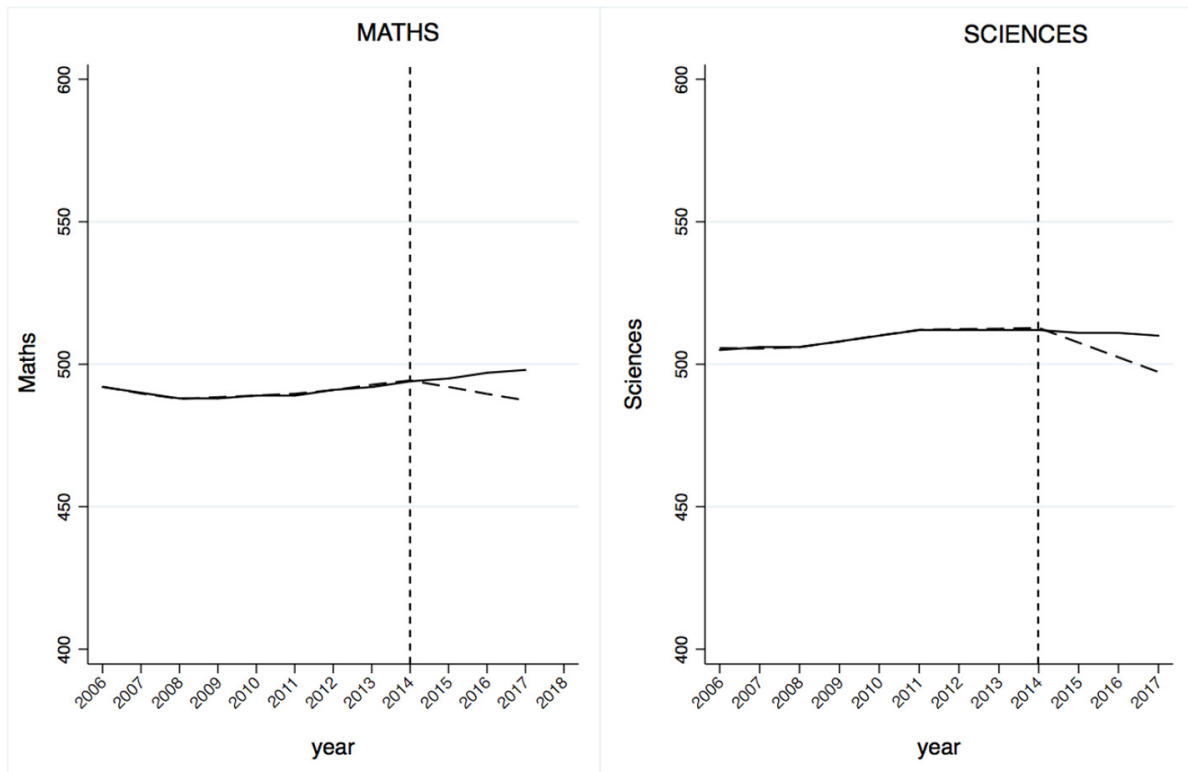

Galicia - - synthetic Galicia

Notes: PISA scores of each installment (every three years) are attributed to competencies acquired by students up to the previous year. The scores are then interpolated between consecutive PISA installments. The figures display the average number of cases officially reported per 10,000 school students corresponding to each region before (upper panels) and after (bottom panels) the intervention year 2015

relatively short period of time. To evaluate further the magnitude of these effects, we can consider that, as a rule of thumb, the average student learning in a year is between onequarter and one-third of a SD of the PISA scale, that is, around 25-30 points on the scale (Woessmann, 2016). According to this, our estimated effects are equivalent to 0.6-0.8 years of learning in maths and around 0.72 to near one year of learning in sciences. On top of that, the economic consequences of these improvements are potentially very relevant. According to the OECD Report-2010 on the long-run impact of improving PISA outcomes (Hanushek and Woessmann, 2010), a modest goal of having all OECD countries boost their average PISA scores by 25 points over the next 20 years would imply an aggregate gain of OECD gross domestic product (GDP) of US\$115tn over the lifetime of the generation born in 2010 (p. 8).

Next, Table 3 displays the estimation results of the DID methodology both for Galicia and for CLM. For the sake of brevity, we only present, in this case, the results corresponding to specification (4). All columns in Table 3 include the full set of covariates also used above, namely, the share of children who have a mobile phone in the region-year, educational public spending and per capita real disposable income of the region-year. A first observation for the Galicia region, Columns (1) and (2), is that there is no evidence of pre-treatment differences in the PISA scores. That is, prior to the mobile phones ban, Galicia did not 


\begin{tabular}{|c|c|c|c|c|c|}
\hline & \multicolumn{2}{|c|}{ Treated region: Galicia } & \multicolumn{2}{|c|}{ Treated region: CLM } & \multirow{3}{*}{$\begin{array}{l}\text { Banning } \\
\text { mobile phones } \\
\text { in schools }\end{array}$} \\
\hline & (1a) & (1b) & (2a) & $(2 \mathrm{~b})$ & \\
\hline & Maths & Sciences & Maths & Sciences & \\
\hline Treated region & $-0.302(7.037)$ & $-0.725(9.360)$ & $-6.760(13.667)$ & 2.785 (11.738) & \\
\hline Pre $\times$ treated $^{\mathrm{a}}$ & 0.859 (2.361) & 3.706 (3.542) & $5.024 * * *(1.291)$ & $10.952 * * *(1.176)$ & \\
\hline Post $\times$ treated $^{b}$ & $6.371^{* *}(2.657)$ & $8.395 *(4.294)$ & $1.983(1.984)$ & $11.623^{* * *}(2.075)$ & \\
\hline Mobile users (\%) & $-0.277 * *(0.114)$ & $-0.431 * *(0.150)$ & $-0.297 * *(0.130)$ & $-0.208(0.143)$ & \\
\hline Educ pub spend & $2.982 * *(1.129)$ & $-0.971(2.804)$ & $2.774 * *$ (1.134) & $0.770(0.800)$ & \\
\hline Income & $31.589(21.754)$ & -11.493 (31.598) & $26.122(29.522)$ & 32.760 (24.661) & \\
\hline Constant & $487.802 * * *(9.705)$ & $502.094 * * *(12.054)$ & 490.704 *** (13.943) & $476.012 * * *(11.941)$ & \\
\hline Year effects & Yes & Yes & Yes & Yes & \\
\hline Region effects & Yes & Yes & Yes & Yes & \\
\hline Observations & 192 & 192 & 192 & 192 & \\
\hline N Regions & 16 & 16 & 16 & 16 & \\
\hline R-squared & 0.938 & 0.903 & 0.938 & 0.914 & \\
\hline Pre-treatment & & & 482 & 481 & \\
\hline avg (treated region) & 491 & 509 & 483 & 481 & \\
\hline \multicolumn{5}{|c|}{$\begin{array}{l}\text { Note: Robust clustered (by region) standard errors in parentheses. } * p<0.10, * * p<0.05 \text { and } * * * p<0.01 \text {. } \\
\text { aPre } \times \text { treated: treated region in the latest years previous to the treatment }(2012,2013,2014 \text { ); if significant, it } \\
\text { indicates non-parallel pre-trends. }{ }^{b} \text { Post } \times \text { treated: treated region in years after the treatment ( } 2015 \text { to } 2017 \text { ). } \\
\text { All the regressions are weighted by the population of each region, year and age-interval. Quantitative } \\
\text { covariates are centered with respect to the annual mean of the variable }\end{array}$} & $\begin{array}{r}\text { Table } 3 . \\
\text { PISA Scores. Diff-in- } \\
\text { diff analysis. Years } \\
\text { 2006-2017 }\end{array}$ \\
\hline
\end{tabular}

display any significant difference in their students' results in the PISA assessments with respect to the rest of the regions in Spain. However, on average, over the after-ban period, the academic results in maths increased by more than 6 points in maths and by more than 8 points in sciences. These are improvements of around 0.5 times the standard deviation of the scores for all regions-years prior to the treatment, and more than four times and three times, respectively, the standard deviation of this region' results from 2006 to 2015. The estimated magnitude of the effects, which are average estimates over the three-year period after the ban, are broadly comparable to those obtained with the SCM: if we average our SCM estimates in Table 2 over the three years post-intervention, we would obtain values of around 7.01 and 8.2 for maths and sciences, respectively. Thus, our results are broadly robust across the two estimation methods.

The results for the CLM region are less conclusive. On the one hand, we estimate positive post-ban effects in both maths and sciences, what would be suggesting some improvement in academic results from 2015 to 2018. However, the estimated effects do not render statistical significance in the case of maths, and the pre-intervention dummy turns out to be statistically significant both in maths and in sciences. Thus, we cannot discern which part of the observed changes does not respond really to a changing trend already initiated before the policy. In any case, the pre-trend dummy for CLM (with PISA scores not available for 2012) does not capture the change in 2015 over 2012 but over six years before, the year 2009. If scores had been stable between 2012 and 2015, no concern would arise on the estimated treatment effect, but we cannot observe this. Our conclusion is that, although the data for CLM also suggest positive effects of the policy, these should be interpreted with caution due to the data limitations.

Interestingly enough, and as mentioned above, the results also suggest that, beyond the in-school use of mobile phones, a higher percentage of children using mobile phones in the region is negatively associated to their academic results. This result would be pointing 
AEA

30,90

\section{8}

towards a negative impact of mobile phone use on academic results, which have implications for further advances on academic achievement given the rising worldwide trends in such use by youngsters. On the other hand, our results point out to a positive impact of educational public spending on the academic performance of students in the PISA assessments on maths. Once all these controls are included in the regressions, no significant effects are found for the region-year levels of per capita real disposable income.

\subsection{Impacts on bullying}

Tables 4 and 5 display the estimated impacts of the mobile phone ban on officially reported cases of bullying for Galicia and CLM, respectively. For both treated regions, we show the impact for each age interval. A first result to notice is that for the under-12 years-old interval, we find no significant treatment effects in neither case. Given that the use of mobile phones is not generalized among children under 12 , we can, in fact, take these results as placebo or falsification checks (the mobile phones ban had not any impact on non-mobile phones users). For school students $12-14$ and 15-17 years old the picture is different. In these cases, and both taking as case study either Galicia or CLM, the results point to a reduction in bullying after the mobile phones ban. Taking into account the pre-ban average values of bullying in each age interval, the estimated impacts would account for significant reductions of around $15 \%$ to $18 \%$ among $12-14$ years old students for Galicia and CLM, respectively, and by around $18 \%$ to $9.5 \%$ among $15-17$ years old teenagers for Galicia and CLM, respectively.

The pre-trend effects are not statistically significant in any of the age intervals, not even of the same sign that the treatment estimated effect in the two older age intervals. Thus, the estimated effects cannot be attributed to differences between the treated and the control regions already initiated prior to the treatment.

In the bottom part of Tables 4 and 5, we further display the results of a series of placebo checks. We estimate the same model on each untreated unit (13 regions) with the same intervention year and pre- and post-periods, and removing the actual treated unit from the control group. In the table, we report the number of regions other than the treated region for which we estimate a negative and significant treatment effect with no significant estimates for the term pre $_{t-1} \times D_{i}$. Only in 1 out of the 13 cases we obtain a negative and significant effect post-intervention. Then, this would point to a probability of 0.076 of finding by chance a comparable result [24]. In addition, the region that turns out to show a significant effect is a different one in each of the age intervals, that is, no region other than the treated ones show significant effects in the two age intervals for which we find them. This suggests that the (scarce) findings in the placebo analysis are more likely to have been found by chance than the estimated effects for Galicia and CLM. Due to the short length of the estimation sample, our DID results here should be taken with caution as suggestive evidence, with further investigation in this issue needed [25].

\section{Conclusions}

Our paper highlights the potential effects of a regional-level non-spending-based policy on a fundamental driver of development, such as the skills in maths and sciences of middleschool students. Our analysis also addresses the potential effects of these policies on bullying incidence, a phenomenon of increasing interest that affects not only educational outcomes but also the social environment among teenagers. The study is focused on two low-wealth regions, which have more limited opportunities to rely on large and sustained levels of educational spending. Alternative policy interventions, affecting complementary 


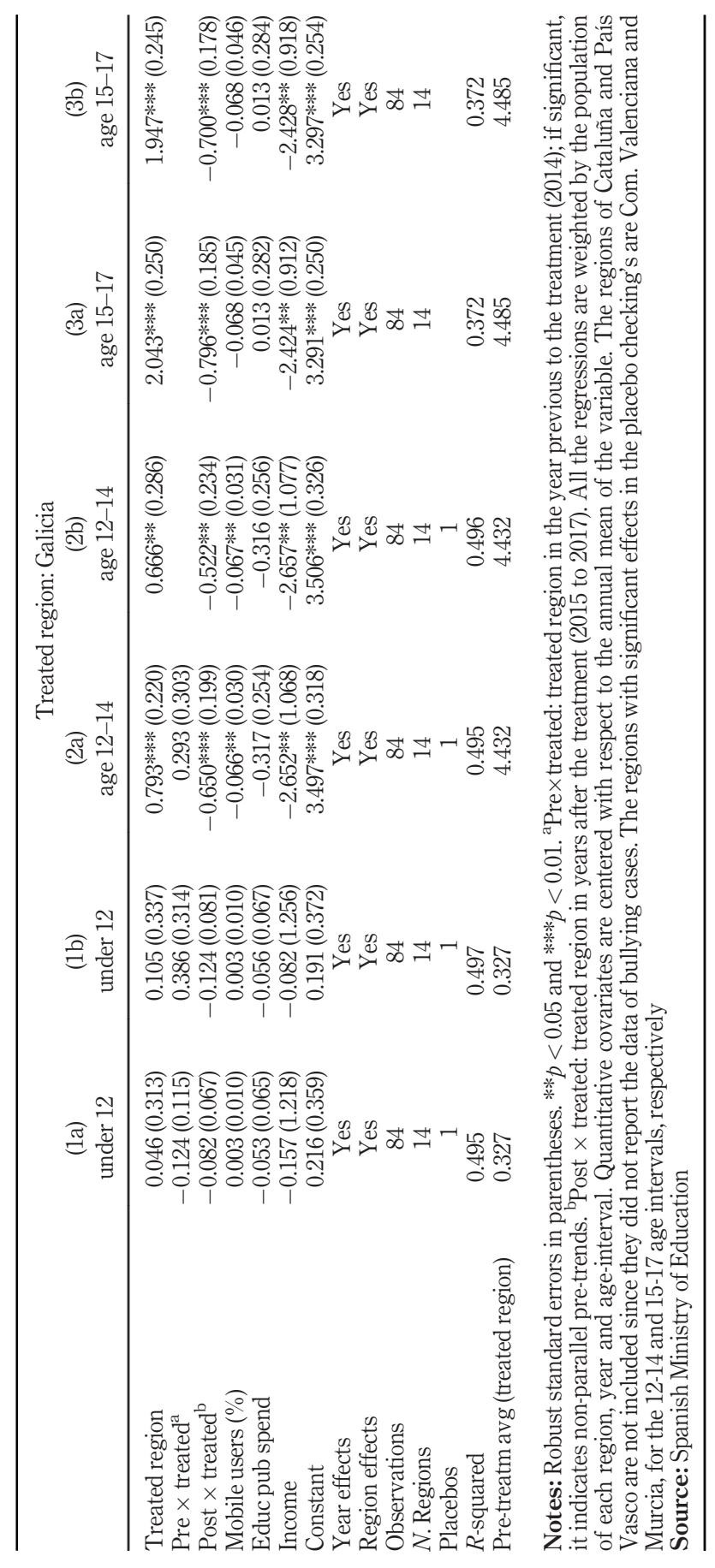

Table 4. Bullying. Diff-in-diff analysis. Years 2012-2017 
AEA

30,90

Table 5.

Bullying. Diff-in-diff analysis. Years 2012-2017

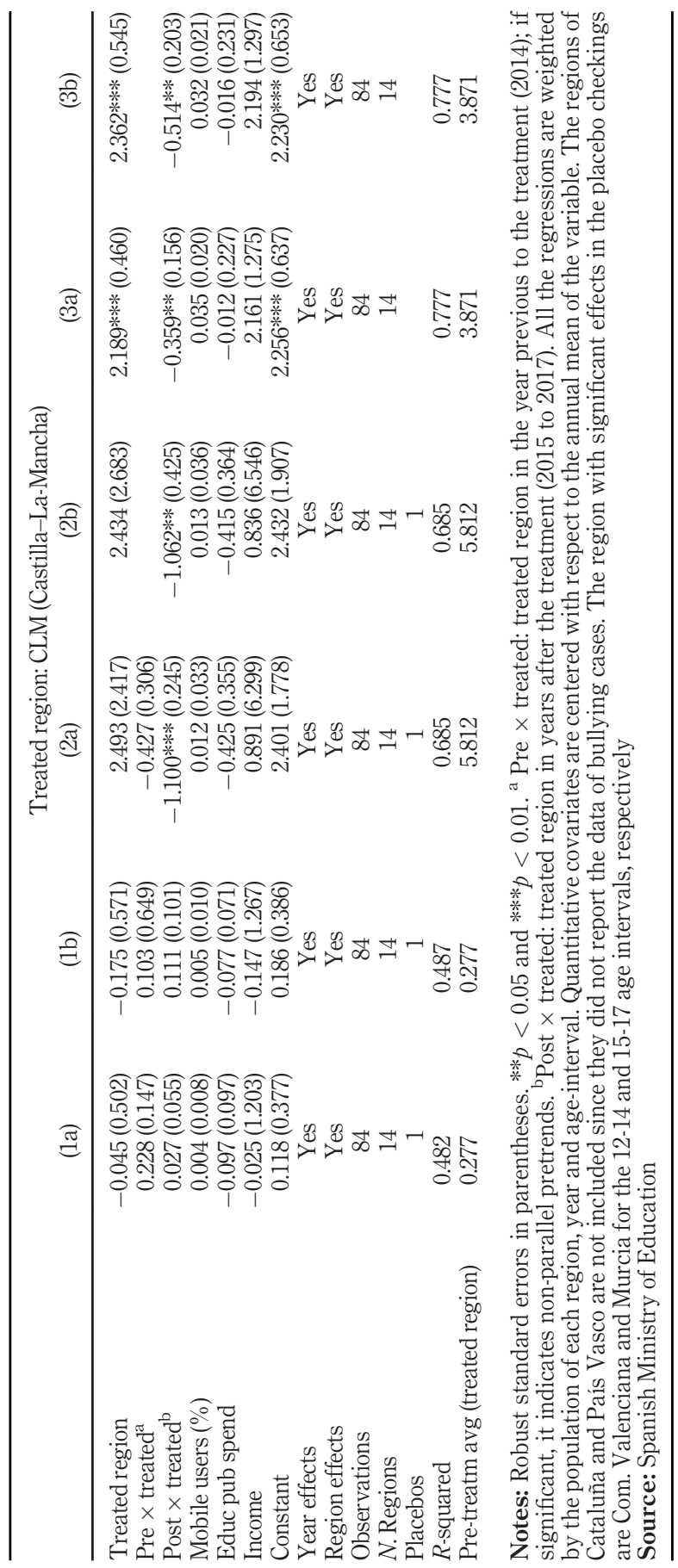


aspects of the educational system such as the policy analyzed here, are thus of particular interest in these cases.

The implementation of this policy in the two mentioned regions in 2015 constitutes a quasi-natural experiment that we exploit to conduct a comparative-case analysis based on the SCM and DID regressions. In particular, we have compared regional PISA scores in maths and sciences and officially reported cases of bullying in the treated and the untreated regions before and after the policy took place. We find that, during the less than three years that the mobile phones ban was in force (from 2015 to 2017), students' scores in Galicia mobile phones in schools improved by around 10 points in maths and 12 points in sciences as compared to a synthetic Galicia that had followed exactly the same trend in these scores before the intervention. We additionally find that bullying incidence fell by around 15\% to $18 \%$ among $12-14$ years old students for Galicia and CLM, respectively, and by around 18\% to 9.5\% among 15-17 years old teenagers for Galicia and CLM, respectively.

Our estimated effects in terms of PISA scores for Galicia are equivalent to 0.6-0.8 years of learning in maths and around 0.72 to near one year of learning in sciences, following Woessmann (2016). The economic consequences of these improvements are potentially very relevant. According to simulations in the OECD Report-2010 on the high costs of low academic performance (Hanushek and Woessmann, 2010), improvements in PISA scores would translate into long-run growth of economies with "implications for the OECD countries as a whole (that) are dramatic" (p. 29).

The policy analyzed in this paper is a timely issue of primary relevance looking ahead on a future where technology will dominate the workplace and everything will be connected and data-driven. This type of policy, as well as similar interventions aimed at reorienting and enhancing the use that the youngest make of the new technologies become a valuable tool that should be evaluated by countries and regions as a mean to contribute to their growth and development.

Although our results are robust to different interpolation strategies in the PISA data series, to changes in the estimation method (SCM or DID) and all they pass a wide set of placebo checks, [26] there are some limitations in the paper that advise us to interpret our findings as suggestive evidence. The first refers to the aggregate nature of the data and, in part as a consequence of this, the modest size of the data samples used in estimation. Thus, replicating this work with longer series of data or finer regional disaggregation would be of most interest for future research. The second derives from the fact that the regulation is not a categorical prohibition of mobile phones in schools but, instead, it gives flexibility to the institutions that want to use mobile phones as a learning tool only. Unfortunately, we lack information on the extent to which schools in the treated regions intensified the use of mobile phones as a learning tool after the policy intervention. Hence, the achievement gains found in this paper should be understood not as much as a result of the prohibition of mobile phones per se but as a result of the enforcement of using mobile phones for learning purposes only. Even with these limitations, our findings are suggestive of the potential beneficial effects of such a cheap policy.

\section{Notes}

1. This paper is based on our previous work Beneito and Vicente-Chirivella (2020).

2. The Government of the Madrid region announced mobile phone bans in schools for the academic year 2020-2021.

3. Lepp et al. (2014) provide some evidence for college students. 
AEA

30,90

4. Fiorini (2010), Fairlie (2005) and Malamud and Pop-Eleches (2011) find large positive effects of home computers on educational outcomes, while Woessmann and Fuchs (2004) and Vigdor et al. (2014) find evidence of negative effects of home computers on educational outcomes. Fairlie and Robinson (2013) do not find significant effects of owning a computer on any educational outcome.

5. Additional complementary uses of mobile technology in education have been studied, for instance, by Bergman (2021), who shows that providing information via text message, phone calls or e-mails to parents about their children's academic progress, produce gains to student effort and achievements.

6. The need not to miss out what is happening in internet has been labeled as FOMO, "fear of missing out."

7. In Spain the primary education goes from 6-11 years old. When children are 12, they change the stage and start the secondary education, in most of the cases moving to another educational center. According to official data from the National Statistics Office, INE, around $30 \%$ of children between 10 and 12 -years-old have mobile phones, while around $64 \%$ of them have it at the age of 12 .

8. Estadística de la Sociedad de la Información y la Comunicación en los Centros Educativos No Universitarios.

9. The contrast between the competencies of the central government and those of the regional governments in Spain, as well as the conflicts that frequently arise between them, has been highlighted by Harguindéguy et al. (2020).

10. Castilla La Mancha, Law 5/2014 of October 9, 2014; Galicia, Decree 17, 2015/1/27 of January 8, 2015).

11. For a summary of schools' practices as regard the use of mobile phones in Spanish regions, available at: www.abc.es/familia/educacion/abci-regula-movil-colegios-cadacomunidad-autonoma-202001131534_noticia.html, last accessed 9 September 2021.

12. The autonomous cities of Ceuta and Melilla in the South, are excluded from our analysis due to its special conditions and anomalous data observed in some of the indicators used in the paper.

13. The Programme for International Student Assessment (PISA), entered by the OECD in 2000, evaluates the competencies of representative samples of 15-year-old students every three years.

14. In preliminary work, we implemented different interpolation strategies. These are: cubic-spline interpolation; and no interpolation at all. The results with these two alternatives confirm a strong robustness of the results that will be presented below, both in quantitative terms and in terms of statistical significance. These results are available upon request.

15. The participation of students in the PISA installments is not compulsory but decided by each government. In Spain, each regional government decides on the participation of their students.

16. In our data set, we only have information about the bullying cases directly reported to the police by a family member of a bullied child. Ideally, it would have been much more desirable that each school had collected all the bullying incidents and then reported it to police forces. In this way, we would have had a more accurate picture of all types of bullying instead of only about particularly aggressive bullying incidents. We are very grateful to an anonymous referee for bringing this point to our attention.

17. INE, Cifras de población y censos detallados.

18. INE, Encuesta sobre equipamiento y uso de tecnologías de la información y comunicación en los hogares. 
19. The financial component includes financial expenses, financial assets and financial liabilities. Some of the expenses included here are interest on debts, expenses for cancellation of debts, default interest and other financial expenses.

20. INE, Estadistica de gasto público en educación, EDUCAbase.

21. INE, Contabilidad regional de los hogares.

22. As evidence of the suitability of the SCM for our type of data, it is worth mentioning that in the seminal paper of Abadie and Gardeazábal (2003), the authors first applied this method to regionyear level data of the 17 Spanish autonomous regions, in their case to analyze the economic costs of conflict in the Basque Country in terms of GDP.

23. For a discussion of the data requirements and advantages of the SCM, see Abadie (2021).

24. Also, in the placebo findings, the estimated impacts are of smaller size than the estimated ones for Galicia and CLM (results are available upon request).

25. As an additional procedure to check for robustness and pre-trend differences, we also selected a "fake" year (2012) to replicate all the estimations. Our estimated results with that fake intervention year rendered no treatment effects for bullying, no effects for PISA results in the case of Galicia and no effects in the SCM for Galicia. In the case of the DID analysis for PISA scores in the region of CLM, coherently with the original findings, the data exhibited pretreatment effects. These results are available upon request.

26. See footnotes 13 and 24 .

\section{References}

Abadie, A. (2021), "Using synthetic controls: feasibility, data requirements, and methodological aspects", Journal of Economic Literature, Vol. 59 No. 2, pp. 391-425.

Abadie, A., Diamond, A. and Hainmueller, J. (2010), "Synthetic control methods for comparative case studies: estimating the effect of California's tobacco control program", Journal of the American Statistical Association, Vol. 105 No. 490, pp. 493-505.

Abadie, A. and Gardeazábal, J. (2003), "The economic costs of conflict: a case study of the Basque Country”, American Economic Review, Vol. 93 No. 1, pp. 113-132.

Abrahamsson, S. (2020), "Distraction or teaching tool: do smartphone bans in schools help students?", available at: https:/sites.google.com/view/saraabrahamsson/research.

Adams, M. (2019), "Threading the Cyber-Needle: protecting children by banning smartphones in school while still embracing technology", McGeorge L. Rev, Vol. 51, p. 245.

Allen, J. (2015), "New York city ends ban on cellphones in public schools", Reuters, available at: https:// in.reuters.com/article/us-usa-new-york-cell-phones/new-york-city-ends-ban-on-cellphones-in-publicschools-idUKKBNOKG1IS20150107.

Amez, S. and Baert, S. (2020), "Smartphone use and academic performance: a literature review", International Journal of Educational Research, Vol. 103, p. 101618.

Barrow, L., Markman, L. and Rouse, C.E. (2009), “Technology's edge: the educational benefits of computer-aided instruction”, American Economic Journal: Economic Policy, Vol. 1 No. 1, pp. 52-74.

Beland, L.P. and Murphy, R. (2016), "Ill communication: technology, distraction and student performance", Labour Economics, Vol. 41, pp. 61-76.

Beneito, P. and Vicente-Chirivella, Ó. (2020), "Banning mobile phones at schools: effects on bullying and academic performance”, (ERICES Working paper No. 04/20), available at: www.erices.es/upload/ workingpaper/99_99_0420.pdf 
AEA

30,90

Bergman, P. (2021), "Parent-child information frictions and human capital investment: evidence from a field experiment”, Journal of Political Economy, Vol. 129 No. 1, pp. 286-322.

Chen, R.S. and Ji, C.H. (2015), "Investigating the relationship between thinking style and personal electronic device use and its implications for academic performance", Computers in Human Behavior, Vol. 52, pp. 177-183.

Chen, Q. and Yan, Z. (2016), "Does multitasking with mobile phones affect learning? A review", Computers in Human Behavior, Vol. 54, pp. 34-42.

Cho, K., Lee, S., Joo, M.H. and Becker, B.J. (2018), "The effects of using mobile devices on student achievement in language learning: a meta-analysis", Education Sciences, Vol. 8 No. 3, p. 105.

Cook, S. (2020), "Cyberbullying facts and statistics for 2020", Website Comparitech.com. Updated: November (11), 2020, available at: www.comparitech.com/internet-providers/ cyberbullying-statistics/

Di Liberto, A. (2008), "Education and Italian regional development", Economics of Education Review, Vol. 27 No. 1, pp. 94-107.

Drydakis, N. (2014), "Bullying at school and labour market outcomes", International Journal of Manpower, Vol. 35 No. 8, pp. 1185-1211.

Fairlie, R.W. (2005), "The effects of home computers on school enrollment", Economics of Education Review, Vol. 24 No. 5, pp. 533-547.

Fairlie, R.W. and Robinson, J. (2013), "Experimental evidence on the effects of home computers on academic achievement among schoolchildren", American Economic Journal: Applied Economics, Vol. 5 No. 3, pp. 211-240.

Fiorini, M. (2010), "The effect of home computer use on children's cognitive and non-cognitive skills", Economics of Education Review, Vol. 29 No. 1, pp. 55-72.

Fryer, R.G. (2013), "Information and student achievement: evidence from a cellular phone experiment (no. w19113)", National Bureau of Economic Research.

Galiani, S. and Quistorff, B. (2017), "The synth_runner package: utilities to automate synthetic control estimation using synth", The Stata Journal: Promoting Communications on Statistics and Stata, Vol. 17 No. 4, pp. 834-849.

Gennaioli, N., La Porta, R., López-de-Silanes, F. and Shleifer, A. (2013), "Human capital and regional development”, The Quarterly Journal of Economics, Vol. 128 No. 1, pp. 105-164.

Hanushek, E.A. and Woessmann, L. (2010), The High Cost of Low Educational Performance: The LongRun Economic Impact of Improving PISA Outcomes, Vol. 2, rue Andre Pascal, F-75775 Paris Cedex 16, OECD Publishing, France.

Harguindéguy, J.B., Rivera, C.F. and Sánchez, A.S. (2020), "So close yet so far: intergovernmental tensions in Spain", Regional Studies, pp. 1-13.

Hawi, N.S. and Samaha, M. (2016), "To excel or not to excel: strong evidence on the adverse effect of smartphone addiction on academic performance", Computers and Education, Vol. 98, pp. 81-89.

Jacobsen, W.C. and Forste, R. (2011), "The wired generation: academic and social outcomes of electronic media use among university students", Cyberpsychology, Behavior, and Social Networking, Vol. 14 No. 5, pp. 275-280.

Junco, R. and Cotten, S.R. (2011), "Perceived academic effects of instant messaging use", Computers and Education, Vol. 56 No. 2, pp. 370-378.

Junco, R. and Cotten, S.R. (2012), "No a 4 U: the relationship between multitasking and academic performance", Computers and Education, Vol. 59 No. 2, pp. 505-514.

Kessel, D., Hardardottir, H.L. and Tyrefors, B. (2020), "The impact of banning mobile phones in Swedish secondary schools", Economics of Education Review, Vol. 77, p. 102009. 
Kuznekoff, J.H. and Titsworth, S. (2013), "The impact of mobile phone usage on student learning", Communication Education, Vol. 62 No. 3, pp. 233-252.

Lepp, A., Barkley, J.E. and Karpinski, A.C. (2014), "The relationship between cell phone use, academic performance, anxiety, and satisfaction with life in college students", Computers in Human Behavior, Vol. 31, pp. 343-350.

Lepp, A., Barkley, J.E. and Karpinski, A.C. (2015), The Relationship between Cell Phone Use and Academic Performance in a Sample of U.S. College Students, SAGE Open, p. 5, 2158244015573169.

Levine, L.E., Waite, B.M. and Bowman, L.L. (2013), "Use of instant messaging predicts self-report but not performance measures of inattention, impulsiveness, and distractibility", Cyberpsychology, Behavior, and Social Networking, Vol. 16 No. 12, pp. 898-903.

López-Bazo, E. and Moreno, R. (2012), "Profitability of investments in education: evidence from Spanish regions", Regional Studies, Vol. 46 No. 10, pp. 1333-1346.

Malamud, O. and Pop-Eleches, C. (2011), "Home computer use and the development of human capital", The Quarterly Journal of Economics, Vol. 126 No. 2, pp. 987-1027.

Milrad, M. (2003), "Mobile learning: challenges, perspectives, and reality", in Nyiri, K. (Ed.), Mobile Learning: Essays on Philosophy, Psychology, and Education, Passagen, Vienna, pp. 151-164.

Muralidharan, K., Singh, A. and Ganimian, A.J. (2019), "Disrupting education? Experimental evidence on technology-aided instruction in India", American Economic Review, Vol. 109 No. 4, pp. $1426-1460$.

OECD, Organisation for Economic Co-operation and Development (2013), PISA 2012 Results in Focus: What 15-Year-Olds Know and What They Can Do with What They Know, OECD, Paris.

Rosen, L.D., Carrier, L.M. and Cheever, N.A. (2013), "Facebook and texting made me do it: Mediainduced task-switching while studying", Computers in Human Behavior, Vol. 29 No. 3, pp. 948-958.

Rowley, K.J., McNeill, S.M., Dufur, M.J., Edmunds, C. and Jarvis, J.A. (2019), "Trends in international PISA scores over time: which countries are actually improving?”, Social Sciences, Vol. 8 No. 8 , p. 231.

Stegmann, J.G. (2019), “ABC-Sociedad. "informe PISA-2018. Los alumnos españoles de 15 años sacan la nota más baja en ciencias desde que existe el informe PISA", available at: www.abc.es/sociedad/ abci-alumnos-espanoles-15-anos-sacan-nota-mas-baja-ciencias-desde-existe-pisa-201912030900_noticia. html (accessed 20 February 2021).

Vigdor, J.L., Ladd, H.F. and Martinez, E. (2014), "Scaling the digital divide: home computer technology and student achievement", Economic Inquiry, Vol. 52 No. 3, pp. 1103-1119.

Woessmann, L. (2016), "The importance of school systems: evidence from international differences in student achievement", Journal of Economic Perspectives, Vol. 30 No. 3, pp. 3-32.

Woessmann, L. and Fuchs, T. (2004), "Computers and student learning: bivariate and multivariate evidence on the availability and use of computers at home and at school", Available at SSRN 619101.

Wood, E., Zivcakova, L., Gentile, P., Archer, K., De Pasquale, D. and Nosko, A. (2012), "Examining the impact of off-task multi-tasking with technology on real-time classroom learning", Computers and Education, Vol. 58 No. 1, pp. 365-374.

\section{Corresponding author}

Óscar Vicente-Chirivella can be contacted at: oscar.vicente@uv.es

For instructions on how to order reprints of this article, please visit our website:

www.emeraldgrouppublishing.com/licensing/reprints.htm

Or contact us for further details: permissions@emeraldinsight.com 